\title{
РАЗВИТИЕ МАЛОГО ПРЕДПРИНИМАТЕЛЬСТВА В СЕЛЬСКИХ ПОСЕЛЕНИЯХ: РЕГИОНАЛЬНЫЙ АСПЕКТ
}

\author{
(c) 2020 Дитц Н. Ф. \\ кандидат экономических наук, доцент, кафедра менеджмента \\ Хакасский государственный университет им. Н. Ф. Катанова, Россия, Абакан
}

В статье рассматривается проблема развития малого предпринимательства в сельских поселениях. Учитывая высокую значимость развития сельского хозяйства, производства отечественного продовольствия, улучшение качества жизни сельского населения, проблема развития малого предпринимательства, государственной поддержки является актуальной, поскольку направлена на решение многих социальных проблем, на улучшение жизни сельских жителей, наполнение рынка продукцией местного сельхозпроизводителя. Каждый регион Российской Федерации имеет как общие подходы в социально - экономическом развитии в соответствии с законодательной базой, так и особенности с учетом бюджетной политики, природных факторов, развития инфраструктуры и др. В статье рассматриваются не только общие тенденции развития малого бизнесе в регионе, но и особенности развития малого предпринимательства в сельских поселениях, барьеры, которые препятствуют развитию малого бизнеса. Отмечено о трудностях с кадровым обеспечением сельского хозяйства. В этой связи приведен опыт работы по подготовке кадров для малого села, использование дистанционных форм обучения по актуальным проблемам. Наряду с решением многих проблем отмечается важность применения интернет ресурсов, что значительно расширяет возможности малого бизнеса на селе, дистанционной формы обучения с широким применением информационных технологий.

Ключевые слова: государственная поддержка, малое предпринимательство, малые села, занятость, кадровая подготовка, сельские территории, дистанционное обучение.

Проблема развития малого предпринимательства в настоящее время особенно актуальна и находит отражение в программных документах, а также в работах ряда исследователей (Афанасьева А., Блинова А.О., Бузника В.М., Свиридова С.А., Шулуса А. и др.) по различным аспектам. Малое предпринимательство имеет представительство в различных сферах экономики и его роль значима с позиции формирования социальной экономики. В Концепции устойчивого развития сельских территорий на период до 2020 года были определены «ключевые проблемы развития сельских территорий» [1]. Создание условий для устойчивого развития сельских территорий является одной из важнейших стратегических целей [1]. На протяжении более двух десятилетий прошли значительные изменения не только в количественном отношении, но и в качественном развитии сельских территорий. Прежде всего, на наш взгляд, можно выделить факторы, влияющие на данный процесс: недостаточно эффективные механизмы управления социально - экономическим развитием сельских территорий, ограничение досту- па жителей села к ресурсам жизнеобеспечения, недостаточно эффективная работа местного самоуправления. Одним из таких факторов является изменение форм хозяйствования на основе изменения форм собственности. Развитие частой формы собственности, с одной стороны давало возможность свободной хозяйственной деятельности на земле, проявление инициативы, самостоятельности, но в то же время должна быть проявлена высокая мера ответственности. Однако, на практике можно было столкнуться часто с безответственностью, инертностью мышления, леностью и иждивенческим настроем со стороны сельского населения. Программы развития малых сел в регионах предусматривают развитие направлений, охватывающие важнейшие сферы и прежде всего производство сельскохозяйственной продукции и ее переработки. Основным источником дохода сельских жителей является личное подсобное хозяйство. Сельский житель обеспечивает себя необходимой сельхозпродукцией. Начиная с конца 80-х и начала 90-х годов двадцатого столетия малый бизнес при поддержке государства развивается 
не только в сфере торговли, общественном питании, но и в сельском хозяйстве. К примеру, получило широкое развитие хлебопечение, изготовление мебели сбор лекарственных трав и др. $\mathrm{B}$ процессе развития малого предпринимательства в аграрной сфере, происходит расширение масштабов предпринимательской деятельности сельского населения. Развитие малого предпринимательства в сельской местности призвано выполнять ряд функций:

- производство сельскохозяйственной продукции с учетом благоприятных природных условий;

- увеличение занятости сельского населения;

- повышение уровня и качество жизни сельского населения;

- развитие инфраструктуры сельских территорий;

- поддержка, сохранение и развитии традиционных видов деятельности в малых селах: народное ремесло, организация и участие в проведении ярмарок сельхозпродукции;

- формирование культурной среды: участие в проведении мероприятий;

- сотрудничество с образовательными учреждениями: проведение обучающих семинаров со школьниками.

В настоящее время население сельских территорий, имеющее опыт предпринимательской деятельности, проявляет инициативу, приспосабливается к кризисным условиям.

По Республике Хакасия в основном прослеживается однородный вид занятий в малых селах: выращивание картофеля, овощей, занятие животноводством. Однако, процесс развития и личного подсобного хозяйства и малого бизнеса на селе сопряжено также с определенными трудностями и имеют ряд причин: старение население, миграция молодежи в мегаполисы, отсутствие навыков работы в сельском хозяйстве и др.

Особенность функционирования малого предпринимательства в настоящее время заключается в том, что нарушена преемственность традиционных видов деятельности на селе, устаревшая информационная база затрудняет возможность быстро адаптироваться и освоить новые технологии. Конечно недостаточность финансовых ресурсов, низкая платежеспособность сельского жителя являются одними из основных причин негативных тенденций. При этом молодежь на селе проявляет интерес к малому бизнесу и более восприимчива к нововведениям, к самостоятельной организации своего потенциала, но отсутствуют доступность к информационной базе по организации малого бизнеса, базовые навыки управленческой деятельности, экономическая и юридическая подготовка, высокая личная инициатива, ответственность и др. В настоящее время в Республике Хакасия прослеживается тенденция к снижению темпов развития малого бизнеса. В течении 2019 года количество субъектов малого и среднего предпринимательства сократилось на 649 ед., или на 3,8\%. Наибольшие потери понесли малые предприятия (их количество сократилось на $11,5 \%)$ количество микрокредитов сократилось на 331 единицу или на 6,7\%. К 2020 году количество малых предприятий сократилось в 1,5 раза. Численность индивидуальных предпринимателей в животноводстве и растениеводстве составило 979 ед. или 91, 8\% 2018 года. Сократилось количество индивидуальных предпринимателей в рыболовстве (97\%\%), производстве мебели (88,8\%) и др. [2] Данная тенденция отражает неустойчивость развития малого бизнеса в сельских территориях, что в целом негативно сказывается на занятость молодежи на селе, возможности иметь стабильный источник дохода. В настоящее время расширение занятости в сельских территориях предполагает мобильность, возможность гибкого графика обучения, доступность получения образовательных кредитов. В этой связи взаимодействие органов местного самоуправления и учебных заведения имеет решающее значение. Вузы имеет определенный опыт взаимодействия по вопросам кадровой подготовки для сельских территорий по СФО. Можно выделить периоды подготовки кадров в зависимости от задач, которые были в целом поставлены по развитию сельских территорий с конца $90-$ х гг.:

1. конец 90-х - 2005 гг. - организация и проведения семинаров по вопросам социально - экономического развития села;

2. 2005-2006 гг. - разработка программ социально-экономического развития. Взаимодействие научного коллектива и специалистов муниципальных образований;

3. 2006-2008 гг. - создание Центра по подготовке и переподготовке управленческих кадров; программы переподготовки предусматривали все важнейшие направления развития сельских территорий; 
4. 2008-2009 гг. - организация рабочей группы по обучению специалистов сельских территорий;

5. 2019-2020 гг. - широкое применение дистанционных форм обучения по подготовке кадров для малого бизнеса сельских территорий.

В настоящее время, на наш взгляд, наиболее актуальной является дистанционная форма работы по обучению специалистов, выпускников школ по актуальным программам.

Таким образом, как видно из таблицы 1.1. можно сделать следующие выводы:

a) Прослеживается общий спад предпринимательства в регионе на 2,9\%;

b) Так количество ИП и КФХ в регионе снизилось на 3,8\% или в абсолютном выражении на 561.

В 2019 году удельный вес в структуре изменился следующим образом:

- численность занятых в малом и среднем предпринимательстве. Так в 2018 году, числу занятых составило 40,6 тыс. человек, однако на начало 2019 года данный показатель составил 37,5 тыс. человек, что меньше на 3,1 тыс. человек в абсолютном значении и $-7,6 \%$ в относительном.

- оборот малых предприятий. Оборот малых предприятий на начало 2018 года составил 28911,5 млн. рублей, а на начало 2019 года 31677,4 млн. рублей, что в абсолютном выражении больше на 2765,9 млн. рублей или +9,6\% в относительном и это является положительным моментом. Как видим по данным статистики прослеживается тенденция к снижению численности занятых в малом бизнесе, в том числе и в сельской местности.

Для улучшения инвестиционного климата органы власти Республики Хакасия предпринимают следующие шаги:

1. Реализуется национальный проект «Малое и среднее предпринимательство и поддержка индивидуальной предпринимательской инициативы», в целях которого привлечено федеральное финансирование в размере 245 млн. рублей.

2. Также в данный проект включены и реализуются мероприятия регионального проекта «Создание системы поддержки фермеров и развитие сельской кооперации».

Факторы, сдерживающие развитие малого предпринимательства в сельской местности:

1) низкий платежеспособный спрос населения - данную проблему руководители бизнеса назвали одной из главных, потому что одним из важнейших условий для развития бизнеса является платежеспособность населения;

2) недостаток финансовых ресурсов - это вторая по важности проблема, которую назвали предприниматели;

3) административные барьеры;

4) проблемы транспортной инфраструктуры в сельской местности;

5) кадры - по мнению предпринимателей, сегодня найти инициативного профессионала своего дела является трудной задачей;

6) недостаточная эффективность государственной поддержки;

7) транспортная инфраструктура недостаточно развита.

Рассмотрев вопросы, касающиеся климата и проблем бизнеса в Республике Хакасия, обратимся к перспективам.

Таким образом, на наш взгляд, перспективным направлением развития для предпринимателей является сельское хозяйство.

Примером государственной поддержки сельского хозяйства малого бизнеса в сельском хозяйстве является принятие Государственной Программы Республики Хакасии «Развитие агропромышленного комплекса Республики Хакасия и социальной сферы на селе» (с изменениями на 30 декабря 2019 года). Данная программа предусматривает «создание условий для увели-

Таблица 1.1. Субъекты малого и среднего предпринимательства в Республике Хакасия за 2018-2019 год [5]

\begin{tabular}{|l|c|c|c|c|}
\hline \multicolumn{1}{|c|}{ Субъекты } & Начало 2018 года & Начало 2019 года & $\begin{array}{c}\text { Изменение } \\
\text { (абсолютное) }\end{array}$ & $\begin{array}{c}\text { Динамика } \\
\text { (в \%) }\end{array}$ \\
\hline $\begin{array}{l}\text { Общее количество субъек- } \\
\text { тов, в том числе }\end{array}$ & 20502 & 19913 & -589 & $-2,9$ \\
\hline ИП (в т.ч. КФХ) & 14893 & 14332 & -561 & $-3,8$ \\
\hline $\begin{array}{l}\text { Малые предприятия (в том } \\
\text { числе микропредприятия) }\end{array}$ & 5577 & 5547 & -30 & $-0,5$ \\
\hline Средние предприятия & 32 & 34 & 2 & $+6,3$ \\
\hline
\end{tabular}


чения количества субъектов малых форм хозяйствования в сельской местности, повышение занятости и дохода, создание системы поддержки фермерских хозяйств и развитие сельской кооперации. Всего направлено 1664689,0 тыс. рублей.» [4]

Таким образом, можно сделать следующие выводы:

На начало 2019 года в республике Хакасия больший удельный вес занимают индивидуальные предприниматели, том числе и КФХ, количество которых сократилось на $3,8 \%$. В разрезе экономической деятельности приоритетное ме- сто заняла в сельской местности заготовка, торговля, общественное питание.

Развитие малого предпринимательства на сельской территории осложняется рядом проблем: низкий платежеспособный спрос населения, административные барьеры, недостаток финансовых средств, неразвита транспортная инфраструктура и другие.

В этой связи, мы предполагаем, что необходимо совершенствовать направления поддержки малого бизнеса на сельских территориях со стороны государства, крупного и среднего бизнеса.

\section{Исследование выполнено при финансовой поддержке РФФИ в рамках научного проекта} № 19-010-00530.

\section{Библиографический список}

1. Концепция устойчивого развития сельских территорий на период до 2020 года, утвержденная Распоряжением Правительства РФ от 30.11.2010 N 2136-p. [Электронный ресурc]. URL: http:/www.consultant.ru/ document/cons_doc_LAW_107793/ (дата обращения: 04.05.2020).

2. Стратегия социально-экономического развития Республики Хакасия до 2020 года, утвержденной постановлением Правительства Республики Хакасия от 25.10.2011 N 700 (с последующими изменениями), во исполнение Указа Президента Российской Федерации от 07.05.2018 N 204 «О национальных целях и стратегических задачах развития Российской Федерации на период до 2024 года». [Электронный ресурс]. URL: https://r-19.ru/authorities/ministry-of-economy-of-the-republic-of-khakassia/useful/strategii/strategiyasotsialno-ekonomicheskogo-razvitiya-respubliki-khakasiya-do-2020-goda.html (дата обращения: 04.05.2020).

3. Постановления Правительства Российской Федерации от 31.05 .2019 N 696 «Об утверждении государственной программы Российской Федерации «Комплексное развитие сельских территорий». [Электронный реcypc]. URL: http://www.consultant.ru/document/cons_doc_LAW_326085/ (дата обращения: 04.05.2020).

4. Государственная программа Республики Хакасия «Развитие агропромышленного комплекса Республики Хакасия и социальной сферы на селе на 2013-2020 годы». ». [Электронный ресурс]. URL: https://r-19.ru/ documents/5879/51988.html (дата обращения: 04.05.2020).

5. Федеральный закон от 08.02.1998 N 14-Ф3 (ред. от 04.11.2019, с изм. от 07.04.2020) «Об обществах с ограниченной ответственностью». [Электронный ресурс]. URL: http://www.consultant.ru/document/cons_doc_ LAW_17819/ (дата обращения: 04.05.2020). 